СЕДОВА Анастасия Павловна - студент 4-го курса направления подготовки «Государственное и муниципальное управление» Института истории и государственного управления Башкирского государственного университета (450077, Россия, г. Уфа, ул. Заки Валиди, 32; sedowa.anastasia2013@ yandex.ru)

ХАБАТУЛЛИНАРиммаРафаилевна-студент 4-гокурсанаправленияподготовки «Государственное и муниципальное управление» Института истории и государственного управления Башкирского государственного университета (450077, Россия, г. Уфа, ул. Заки Валиди, 32; khabatullina@mail.ru) СИЗОНЕНКО Зарина Лероновна - кандидат социологических наук, доцент; доцент кафедры государственного управления Института истории и государственного управления Башкирского государственного университета (450077, Россия, г. Уфа, ул. Заки Валиди, 32; marian01@таil.ru)

\title{
ЭТНИЧНОСТЬ И РЕЛИГИОЗНОСТЬ КАК КРИТЕРИИ ВЫБОРА БРАЧНОГО ПАРТНЕРА У СОВРЕМЕННОЙ МОЛОДЕЖИ
}

\begin{abstract}
Аннотация. В статье рассматривается роль социокультурных факторов в брачно-семейных установках современной молодежи. Авторы приводят результаты разведывательного интернет-опроса, показывающие значимость таких критериев брачного выбора как этническая и религиозная идентичности потенциального партнера. Все опрошенные молодые люди указывали на толерантные отношения к людям иного вероисповедания и этнической принадлежности, но при этом большинство заявили о стремлении выбрать спутника жизни из “своего круга» - этноса и конфессии.
\end{abstract}

Ключевые слова: этничность, национальность, молодежь, религия, брачный выбор, межнациональный брак

$\Phi$ ормированию брачных отношений предшествуют поиск и определение партнера. При этом социальные действия индивида, осуществляющего брачный выбор, детерминируются объективными социально-экономическими и политическими условиями, а также его субъективными представлениями и установками. Механизм данного процесса и его результаты были рассмотрены учеными с различных позиций: сквозь призму психологических [Китова, Балова 2011] либо демографических представлений [Козлов 1999: 64 - 77], в экономических категориях [Беккер 2003: 383 - 437], с позиций рационального мышления ${ }^{1}$. Статусные характеристики потенциальных и реальных брачных партнеров изучались социологами [Бурханова 2011: 104 - 109], но сложность предмета исследования по-прежнему детерминирует интерес к данной проблематике. Попытки моделирования указанного процесса не привели к созданию универсальной модели, учитывающей разнообразие внешней среды, априори изменчивой и динамично развивающейся, что, в свою очередь, обуславливает необходимость многократного обращения к проблеме критериев брачного выбора и их изучения.

Фактически все физически зрелое население может быть задействовано на брачном рынке - воображаемом пространстве, где индивиды обоих полов ищут «вторую половину», нацеленные на формирование супружеских отношений. При этом каждый потенциальный и реальный участник брачного рынка имеет характеристики, определяющие уровень его конкурентоспособности и, соответственно, детерминирующие результативность брачного отбора.

1 Рощин С.Ю., Рощина Я.М. Брачный рынок в России: выбор партнера и факторы успеха. М.: ГУ ВШЭ, 2006. Доступ: https://www.hse.ru/data/2010/05/05/1216427460/ WP4_2006_04.pdf (проверено: 06.07.2020). 
Исследование процесса брачного выбора в полиэтничном социуме требует учета этнической и конфессиональной составляющей в характеристике его участников и обладает рядом особенностей, обусловленных современным состоянием глобализирующегося и трансформирующегося социума.

Как и любая сфера социального взаимодействия, брачный рынок подвержен влиянию внешних условий на его становление и функционирование. Российское общество в последние три десятилетия испытало влияние множества факторов, трансформировавших не только его структуру, но и во многом изменивших характер взаимодействия субъектов брачных отношений. Распад Советского Союза, рыночная экономика и глобализация привели к формированию новых социальных практик, изменению приоритетов в ценностных ориентациях. Объективные факторы брачного выбора обусловлены такими характеристиками брачного рынка, как брачные нормы, ценности, уровень разводимости, рождаемости, пространство брачного выбора, либерализация половой морали в теории и на практике; субъективные - это социально детерминированные представления о браке, доминирующие в различных группах, прежде всего среди молодежи.

Наблюдения показывают, что россияне, в том числе молодежь, стали чаще задаваться вопросом о своем происхождении: например, интересоваться генеалогией ${ }^{1}$. При этом поддерживаются этнические и религиозные традиции, и их значимость не только не уменьшается, напротив, наблюдается тенденция к возрождению забытых ритуалов и обычаев. Трудно не согласиться с мнением В.Т. Лисовского по поводу религиозности молодежи: «Проблема религиозности молодежи весьма значима в масштабе всей Земли, она не просто отражает острые процессы сакрализации и секуляризации в отдельной стране. Масштабность этой проблемы явно недооценивается социологами, которые с удовлетворением пишут о расширяющейся секуляризации светского мира» [Лисовский 1996: 299]. Таким образом, необходимость научного осмысления вопросов межнационального и межконфессионального взаимодействия, прогнозирования тенденций их развития в контексте семейно-брачных отношений по-прежнему актуальны.

Перспективы развития социально-демографических и этнокультурных процессов зависят прежде всего от установок и намерений молодежи, но сохранение этнической культуры напрямую связано с функционированием семьи. Бытие этносов соотносится с семьей, сохранить семью - значит сохранить народ. Поэтому в основу концепции проведенного исследования положен следующий тезис: образование межэтнических/межнациональных семей непосредственно влияет на процессы сохранения или вымирания этнически однородных народов. Соответственно целью проведенного в 2020 году в рамках подготовки к всероссийской молодежной научной школе-конференции на тему «Соотношение конфессиональной, этнической, региональной и гражданской общероссийской идентичности в общественной и политической среде Республики Башкортостан» ${ }^{2}$ интернет-опроса было выявление значимости этнической принадлежности и вероисповедания как критериев

\footnotetext{
1 Россияне заинтересовались изучением своего рода. Российская газета - Федеральный выпуск. № 210(7078). Доступ: https://rg.ru/2016/09/18/semi-gotovy-tratit-ogromnye-dengichtoby-uznat-o-svoih-predkah.html (проверено 01.12.2020).

2 Всероссийская молодежная научная школа-конференция «Соотношение конфессиональной, этнической, региональной и гражданской общероссийской идентичности в общественной и политической среде Республики Башкортостан» была проведена 26-28 марта 2020 года в г. Уфа Республики Башкортостан при поддержке Школы молодого этнополитолога в Республике Башкортостан (грант Фонда президентских грантов 19-2-022447).
} 
выбора брачного партнера. В опросе приняли участие 315 респондентов (в возрасте от 18 до 35 лет), выборка стихийная. Проведенное исследование носит поисковый характер, но в целом отражает тенденции в рассматриваемой сфере.

Как показал опрос, 71 \% респондентов не считает необходимым проводить религиозные обряды венчания, никаха и иных (соответствующих вероисповеданию). Интересен тот факт, что у $24 \%$ опрошенных родители считают религиозные обряды обязательными, и дети непременно должны их соблюдать при заключении брака. 75 \% родителей респондентов относятся к обрядам нейтрально, а $1 \%$ старшего поколения высказывается категорически против проведения религиозных обрядов и ритуалов. При этом $90 \%$ опрошенных не согласны менять вероисповедание, если брачный партнер окажется приверженцем другой конфессии. Фактически получаются противоречивые данные. С одной стороны, молодые люди заявляют о нейтральном, почти равнодушном отношении к религиозным обрядам, но с другой - готовы проявить принципиальность, если возникнет вопрос о необходимости изменить религиозную идентификацию.

Можно сделать вывод о том, что толерантность в вопросах этнического и конфессионального многообразия имеет некие пределы: если человек окажется перед концептуальным выбором, в нужный момент он вспоминает о своем происхождении. Вопрос, несомненно, требует отдельного, более глубокого рассмотрения, но на поверхности оказываются факторы потенциальных конфликтов. По данным проведенного опроса, $34 \%$ респондентов уже состоят в отношениях с представителем другой национальности и иных религиозных взглядов, $48 \%$ состоят в отношениях с партнером своей национальности, при этом среди таких пар есть противоречия в вопросах вероисповедания. $18 \%$ респондентов не состоят в семейно-брачных отношениях.

При конструировании обобщенной модели влияния этнических и религиозных норм на брачную структуру необходимо учесть тот факт, что культуры разных этносов и конфессий отличаются друг от друга еще и тем, что допустимы ли в них в принципе повторные браки или нет. Если повторные браки допустимы, та совокупность, в которой происходит выбор брачного партнера, является довольно-таки широкой и включает в себя состоящих и не состоящих в браке людей. Первоначально индивид доступен для брака, то есть является потенциальным участником процесса брачного выбора, вне зависимости от того, состоит он в браке или нет.

В культурах, где повторные браки не допускаются, в условиях традиционной, жесткой моногамии, пространство возможного выбора не включает в себя тех, кто уже состоит в браке. Индивид попадает в эту совокупность по достижении установленного законом или обычаем в рамках этнической/религиозной культуры брачного возраста и покидает её, вступив в брак. В современном мире, где стирается граница между западным и восточным типом, историческая тенденция заключается в переходе от строгой моногамии, когда вступление в повторный брак было затруднено, к моногамии серийной, когда повторные браки стали обычным делом. Что касается степени свободы индивидуального выбора, в этом отношении между общностями наблюдаются различия. В некоторых культурах, а в прошлом практически повсюду, преобладают браки, обусловленные выбором родителей или других родственников, под чьей опекой находятся молодые люди. Такие браки априори были этнически однородными. Можно предположить, что межнациональные (межэтнические) браки в прошлом были скорее исключением.

Вообще, сама проблематика межэтнической брачности заслуживает отдель- 
ного рассмотрения. Как справедливо отмечают ученые, «точных данных о количестве таких браков не было и нет, однако статистика подтверждает, что в России количество межнациональных браков стало расти уже после победы Великой Октябрьской социалистической революции, превратившись к настоящему времени в широко распространенное социальное явление. Интересно, что именно в этот период традиционная семья практически прекращает свое существование, сменяясь современным типом семьи с явно ослабленными институциональными характеристиками, межнациональная же семья начинает формироваться именно как социальный институт. В 50 -е годы в бывшем СССР межнациональным был каждый 10-й брак, в 80-е годы - уже каждый 7-й, а в некоторых республиках - каждый 5-й. Республика Башкортостан, согласно материалам переписи населения 1989 года, становится второй в Волго-Уральском регионе по численности межнациональных браков. Каждый третий ребенок рождается в межнациональной семье (на 1 млн 50,3 тыс. семей, учтенных переписью, пришлось 262,4 тыс. межнациональных семей)» [Сизоненко 2007: 141].

Ученые дают следующее объяснение тенденций в сфере брачных отношений: «не вызывает сомнений, что рост межнациональной брачности обусловлен прежде всего отменой частной собственности - главной основы экономической и моральной зависимости молодых людей от воли родителей при вступлении в брак. Советская власть упразднила самое действенное наказание за нарушение семейного кодекса, и результат не замедлил сказаться: молодые семьи, скрепленные одобряемым родителями браком и не одобряемым, оказались в равном экономическом, политическом и социальном положении, что в свою очередь спровоцировало свободу относительно самостоятельного выбора брачного партнера. Помимо указанных доводов весомую роль в расширении национально-смешанной брачности сыграло ослабленное положение института религии, утрата им регламентирующего влияния в сфере межличностных отношений людей разной этнической принадлежности. Изменилась и позиция государства: при царизме правительство, боясь сближения и совместной борьбы народов против феодально-колониального гнета, запрещало смешанные браки (сильному стеснению подвергал браки башкир с казанскими татарами-переселенцами Указ от 11 февраля 1736 года, брак разрешался лишь с позволения казанского губернатора), при Советской власти положение резко изменилось. Межнациональные браки могли способствовать укреплению дружбы и взаимопонимания между людьми различных национальностей.

Межнациональная семья должна была стать и стала своеобразным символом дружбы народов многонационального Союза Советских Социалистических Республик. Однако в 90-е годы после распада Союза отношение к межнациональным семьям изменилось, что связано с процессами пробуждения национального и религиозного самосознания. Тем не менее, межнациональная семья - распространенное явление в современном социуме...» [Абдрахманов, Сизоненко, Юлдашева 2011: 55 - 57].

Результаты проведенного интернет-опроса свидетельствуют о том, что молодые люди до определенного момента не задумываются о своем отношении к вопросам вероисповедания и этнической идентификации, однако по мере взросления эти вопросы могут актуализироваться. Особенно значимым данный вопрос может оказаться при выборе брачного партнера. Но опять же, на стадии знакомства и добрачных отношений скорее всего доминирует толерантность, однако впоследствии могут проявиться принципиальные разногласия по организации быта, воспитанию детей и т.д. Данная проблематика 
освещалась в исследованиях этносоциологов ${ }^{1}$. Вполне оправдано появление в современной науке такой научной дисциплины как этнопсихология ${ }^{2}$, в рамках которой могут быть выявлены определенные поведенческие закономерности, характерные для представителей этнических групп. Это, безусловно, перспективное направление научных изысканий.

Важно понимать, что исследования вопросов этнической и религиозной идентификации отличаются сложностью как в организации, так и концептуализации понятийного аппарата, объекта и предмета. Многообразие стилей отношений, субъективизм в оценке собственной этнокультурной идентичности требуют намеренного упрощения некоторых терминов для обеспечения доступности языка анкеты для респондентов. Некорректные формулировки могут быть неверно интерпретированы опрашиваемыми, что может спровоцировать конфликтную ситуацию. Объективность и надежность результатов зависят от того, насколько серьезно молодежь относится к самому проблемному вопросу, понимают ли респонденты его значимость и насколько искренне отвечают. Можно предположить, что релевантные данные могут быть получены экспериментальным путем, что позволит, например, выявить глубинные причинно-следственные связи и детерминанты выбора брачного партнера. Тем не менее, проведенное исследование все же позволяет сделать вывод о значимости этнической и религиозной идентификации для современной молодежи, что с большой вероятностью проявится в процессе формирования и развития семейно-брачных отношений при доминирующих в социуме установках на толерантность.

Таким образом, демаркация по линии «свой-чужой» по признаку этнической принадлежности и вероисповеданию у большинства опрошенных актуализируется при выборе брачного партнера, но в повседневных контактах и иных сферах жизнедеятельности может не проявляться. Такого рода тенденции уже отмечались, но возрастающая статистика по межнациональной брачности как будто бы противоречила им. Ситуация проясняется при определении этнической идентификации партнеров: она свидетельствует о том, что в межнациональные браки вступают, как правило, те, у кого в родословной представители нескольких этносов, что не позволяет документально однозначно определить национальную принадлежность индивида. Это явление как «вторичный эффект» межнациональной брачности было описано в научных публикациях [Сизоненко 2007: 142] и подтверждается результатами данного опроса.

Статья публикуется при поддержке Школы молодого этнополитолога в Республике Башкортостан (грант Фонда президентских грантов 19-2-022447).

\section{Список литературы}

Абалакина М.А., Агеев В.С. 1989. Романтическая любовь, полоролевые стереотипы и динамика предбрачных отношений. Идеологические и психологические аспекты исследования массового сознания. М.: ИНИОН. С. 112-185.

\footnotetext{
1 Губогло М. Этносоциология и этнополитология в орбите социологического знания // Русин. 2006. №3. Доступ: https://cyberleninka.ru/article/n/etnosotsiologiya-i-etnopolitologiyav-orbite-sotsiologicheskogo-znaniya (проверено 12.10.2020).

2 Баракатова Д.А. Этнопсихология как наука // PEM: Psychology. Educology.Medicine. 2013. №1-1. Доступ: https://cyberleninka.ru/article/n/etnopsihologiya-kak-nauka (проверено 12.10.2020)
} 
Абдрахманов Д.М., Сизоненко 3.Л., Юлдашева О.Н. 2011. Социальные технологии укрепления межнационального согласия: монография. Уфа: Диалог. 244 с. Доступ: https://www.elibrary.ru/item.asp?id=22974971 (проверено 25.04.2020).

Баракатова Д.А. 2013. Этнопсихология как наука. PEM: Psychology. Educology. Medicine.№ 1-1.Доступ: https://cyberleninka.ru/article/n/etnopsihologiya-kaknauka (проверено 12.10.2020).

Бурханова Ф.Б. 2011. Создание семьи в современных условиях. - Человеческий капитал. № 10. С. 104-109.

Губогло М. 2006. Этносоциология и этнополитология в орбите социологического знания. Русин. №3. Доступ: https://cyberleninka.ru/article/n/ etnosotsiologiya-i-etnopolitologiya-v-orbite-sotsiologicheskogo-znaniya (проверено 12.10.2020).

Беккер Г.С. 2003. Человеческое поведение: экономический подход. Избранные труды по экономической теории: пер. с англ. Составитель, науч. ред., послесл. Р.И. Капелюшников / предисл. М.И. Левин. М.: ГУ ВШЭ. 673 с.

Бикметов Е.Ю., Лукьянов А.В. 2019. Духовный, социокультурный и языковой контекст развития научного знания: монография. Уфа: УГАТУ. 225 с.

Волкова А.Н. 2008. Психологическое консультирование семейных конфликтов. Вестник ЛГУ им. А.С. Пушкина. №2 (Психология). Доступ: https:// cyberleninka.ru/article/n/psihologicheskoe-konsultirovanie-semeynyh-konfliktov (проверено: 28.05.2020).

Дробижева Л.М. 1991. Этническое самосознание русских в современных условиях: идеология и практика. Советская этнография. № 1. С.3-13.

Ильин Е.П. 2003. Дифференциальная психофизиология мужчины и женшины. СПб.: Питер. 544 с.

Китова Д.А., Балова Д.Ю. 2011. Психологические особенности представлений студентов о создании семьи. Прикладная психология и психоанализ. Электрон.науч. журн., № 1. Доступ: URL: http://ppip.idnk.ru, (проверено: 02.05.2012).

Козлов Г.А. 1999. Модели брачного рынка в демографическом моделировании. Экономика и математические методы. № 4. С. 64-77.

Лисовский В.Т. 1996. Социология молодежи. С.-Пб.: Санкт-Петербургский университет. $361 \mathrm{c.}$

Ростовская Т.К., Шимановская Я.В. 2017. Брачно-семейные отношения современной молодежи. Научные ведомости БелГУ. Серия: Философия. Социология. Право. №3 (252). Доступ: https://cyberleninka.ru/article/n/brachno-semeynyeotnosheniya-sovremennoy-molodezhi (проверено: 11.03.2020).

Рощин С.Ю., Рощина Я.М. 2006. Брачный рынок в России: выбор партнера и факторы успеха. М.: ГУ ВШЭ. Доступ: https://www.hse.ru/ data/2010/05/05/1216427460/WP4_2006_04.pdf (проверено: 06.07.2020).

Сизоненко 3.Л. 2007. Межнациональная семья в крупном городе. Социологические исследования. № 2. С. 140-142.

Россияне заинтересовались изучением своего рода. Российская газета Федеральный выпуск. № 210(7078). Доступ: https://rg.ru/2016/09/18/semigotovy-tratit-ogromnye-dengi-chtoby-uznat-o-svoih-predkah.html (проверено 01.12.2020). 
SEDOVA Anastasia Pavlovna, student in the «State and Municipal Administration» training at the Institute of History and Public Administration, Bashkir State University (32, Zaki Validi St., Ufa, Russia, 450077; sedowa.anastasia2013@ yandex.ru)

HABATULLINA Rimma Rafaileevna, student in the «State and Municipal Administration» of the Institute of History and Public Administration, Bashkir State University ((32, Zaki Validi St., Ufa, Russia, 450077 ; khabatullina@mail.ru)

SIZONENKO Sarina Leronovna, Cand.Sci. (Soc.), Associate Professor; Associate Professor of the Department of State Administration at the Institute of History and Public Administration, Bashkir State University ((32, Zaki Validi St., Ufa, Russia, 450077; marian01@mail.ru)

\title{
ETHNICITY AND RELIGIOSITY AS CRITERIA FOR CHOOSING A MARRIAGE PARTNER AMONG THE MODERN YOUTH
}

\begin{abstract}
The article examines the role of sociocultural factors in the marriage and family attitudes of modern youth. The authors present the results of an intelligence Internet survey showing the importance of such criteria for marriage choice as the ethnic and religious identity of a potential partner. All interviewed young people pointed to the tolerant attitude towards people of another religion and ethnicity, but the majority stated their desire to choose a life partner from "their circle" - ethnos and confession. According to the authors, studies on these issues among the youth, do not allow to obtain the objective data. The reason lies in the characteristics of the young audience itself. It all depends on how seriously young people refers to the problematic question, whether its significance is understood, and whether there is a desire to sincerely answer.
\end{abstract}

Keywords: ethnicity, nationality, youth, religion, marriage choice, intermarriage 